\title{
Outcome of Snodgrass Repair of Distal Penile Hypospadias with Stented and Unstented Urethra
}

\author{
Gamal A.M Morsi, Mohamed A. Abdel Azez, Hussein A. Galal, Alsayed M.H Hathout, \\ Mourad M. Mourad and Mo'men Roshdy Qobaissy \\ Department of Urology, Faculty of Medicine - Al-Azhar University \\ Corresponding author: Mo’men Roshdy Qobaissy, Mobile: (+20)01116446440, E-Mail: momnroshdy@gmail.com
}

\begin{abstract}
Background: Hypospadias is the most common congenital malformation of penile shaft occurring in 1 per 300 male births; it is considered a common clinical problem as it causes not only functional problems but also psychological problems for parents.

Objective: The objectives of this study is to review the result of TIP repair of distal penile hypospadias in terms of outcome and complications of stenting and unstenting the urethra.

Patients and methods: As a prospective randomized study; this study has included patients with distal penile hypospadias operated with Snodgrass between year 2011-2018 and had divided to (group A) included 40 patients operated upon with stent preservation for a week (group B) was 20 patients with stent removed at the end of the operation.

Results: Regarding group (A) the stent of 10 cases had slipped at the first 8 hour postoperative so they have been added to the count of (group B) and considered as unstented repair. It is clear here in our study that meatal stenosis rate were different from Snodgrass rate but were similar to other published studies. Other comparable items as fistula rate, urinary retention and hospital stay, were the same as published studies.

Conclusion: It could tell that removing the catheter can reduce bladder spasm , urinary tract infections, and patient discomfort and improve the familiar compliance without increasing acute retention episodes and fistula rate, so that at least in some cases specially in distal types, leaving stent can be avoided.
\end{abstract}

Keywords: Snodgrass, Distal Hypospadias, Unstented Urethra

\section{INTRODUCTION}

Hypospadias is the most common congenital malformation of penile shaft occurring in 1 per 300 male births; it is considered a common clinical problem as it causes not only functional problems but also psychological problems for patients and their parents. Its incidence is on rise with increasing environmental pollution as the suspected cause. The Birth Defects Monitoring Program (BDMP) has reported a doubling of the rate of hypospadias incidence since $1970^{(\mathbf{1})}$.

In the classical method of tubularized incised plate (TIP) repair of distal penile hypospadias, to prevent urethral stenosis and fistula formation, a stent was used. In a recent description of TIP procedure by Snodgrass himself, he recommended stent placement for about a week to drain urinary bladder and to act as a scaffold for urothelial healing ${ }^{(2)}$.

Newer studies debate the necessity of stenting in distal hypospadias repair, for some surgeons they claimed that the procedure can be performed without leaving a stent, without compromising the surgical outcome, and the necessity of leaving stent after end of operation is somewhat questionable ${ }^{(3)}$.

Aslan et al. ${ }^{(4)}$ studied the factors which determine the duration of stent placement post TIP urethroplasty; they found that the patients with short term catheterization had similar outcomes to patients with stents for 7- 14 days ${ }^{(4)}$.

On the other hand, Buson et al. ${ }^{(5)}$ in 1994 and Minevich et al. ${ }^{(6)}$ in 1999 reported that urethral stenting in distal hypospadias repair decrease the risk of fistula formation while adding only minimal morbidity ${ }^{(6)}$.

So, the role of stent in TIP technique are highly debated with no clear guideline for distal hypospadias repair and if the absence of stent does not affect the urological results, the impact on postoperative discomfort remains to be evaluated in a comparative trials .

\section{AIM OF THE WORK}

The aim of this randomized prospective study is to compare stenting and unstenting urethra in Snodgrass technique for distal penile hypospadias and to display results for each method.

\section{PATIENTS AND METHODS}

\section{Study design and period:}

As a prospective randomized study; this study has included patients with distal penile hypospadias operated with Snodgrass technique (TIP repair) between years 2011-2018 and were divided in two groups, the first group (group A) included 40 patients operated upon with stent preservation for a week and the other group was 20 patients with stent removed at the end of the operation. The stent of 
10 cases of first group had slipped at the first 8 hour postoperative so they have been added to second group (group B) and considered as unstented repair, so that:

- Group (A): included 30 patients underwent stented TIP

- Group (B): included 30 patients underwent unstented TIP.

Study area: This study had been carried out at Assuit Urology Department Al-Azhar University Hospital and Assuit Urology Department Police Hospital.

Inclusion criteria:

- Children age $>6$ months.

- Fresh distal penile hypospadias.

- Wide and healthy urethral plate.

- Cases with normal and stenosed urethral meatus.

- Uncircumcised children.

Exclusion criteria

We exclude from our study the patients with following criteria:

- Patients with penile curvature.

- Patients with unhealthy urethral plate.

- Patient with ulcerated, narrow or short urethral plate.

- Patients with penile torsion and penoscrotal transposition

- Association of other congenital anomalies (Cryptorchidism, inguinal hernia, persistent Mullerian structures).

- Echocardiographic abnormal finding for 6 months patients.

Ethical consideration and Counseling of the parents:

After The approval of the Ethical Committee of our Faculty, the nature of the study, the goals of the surgery, plan of surgical repair, any possible modifications during surgery, common complications and their treatments, period of hospitalization, postoperative protocol and the expected results and complications were explained to their parents and a written consent form was obtained before enrollment into study.

\section{Preoperative assessment:}

Preoperative assessment include measurement of the size of the phallus, glans clef (flat, incomplete, or complete), site and size of the meatus (type of hypospadias and meatal stenosis or mega-meatus), urethral plate width $(<1 \mathrm{~cm}$ or $\geq 1$ $\mathrm{cm}$ ), presence of chordee, prepuce (complete, incomplete, circumcised), penile torsion (clockwise, anticlockwise), shape of the scrotum (normal, penoscrotal transposition), and associated anomalies (cryptorchidism, inguinal hernia, persistent Mullerian structures) .

All patients enrolled in this study had been

undergone the following details:

Full history with emphasis on:

Present history: the condition was recognized since birth.

Past History: any associated medical condition or other recognized congenital anomalies.

Family history.

\section{Physical examination:}

General examination:

- Vital signs

- Abdominal examination

- Head and neck examination

- Examination of other systems

Local examination:

- Penis:

- Abnormal meatus:

- Urethral plate :

- Glans :

- Scrotum :

The diagnostic evaluation also included an assessment of associated anomalies, such as

- Cryptorchidism

- Patent processus vaginalis

- Ambiguous genitalia. Our 60 patients didn't have any associated congenital anomali

\section{Perioperative antibiotics:}

A third generation cephalosporin

(cefotaxime) was given to all cases I V. intraoperative, with continuing the dose till removing the stent for stented group and for discharging for unstented group.

Magnification: Three power optical surgical loupe was used in all cases.

Procedure: At the end of the procedure using Snodgrass classic technique, in group A we left a urethral catheter according to the urethral diameter (usually 6:10 Fr silicon catheter was used) and in group B we didn't leave urethral stent. The urethral catheter was left 7 to 10 days after the procedure.

\section{Follow up}

Early: The early evaluation included observation for bleeding, infection, bladder spasm, stent migration, painful voiding, urinary retention and extravasation.

Patient were examined weekly in the first month then monthly in the next three months and when necessary, then once yearly till five years. 
Late: All patients were followed from 6-12 months with a mean follow up of 7 months by monthly assessment of absence of the urethral stricture via:

- The caliber and direction of the urine stream

- The post voiding residual urine (by U / S).

- All the patients were evaluated with pelviabdominal ultrasonography 3 months after the procedure.

\section{Statistical analysis}

The clinical data were recorded on a report form. These data were tabulated and analyzed using the computer program SPSS (Statistical package for social science) version 18. Descriptive statistics were calculated for the data in the form of mean and standard deviation for quantitative data, which were compared by T-test, and in the form of frequency and distribution for qualitative data, which were compared by chi square test or Fisher exact test (to compare categorical data when one cell is less than five). $\mathrm{P}$ value $<0.05$ was considered statistically significant while $>0.05$ statistically insignificant, and $\mathrm{P}$ value $<0.01$ was considered highly significant.

\section{RESULTS}

In this study 60 patients with hypospadias were divided randomly into 2 groups:

- Group (A): Stented Snodgrass

- Group (B): Unstented Snodgrass

Both groups (A) and (B) were homogenous with no statistically significant difference between them as regard age, local examination of the glans (shape, transverse diameter), local examination of the urethral plate (length, width, shape), local examination of the skin of the penis (development of the skin, circumcision, chordee ) and size of the penis (Table 1-3).

Table (1): comparison between two study groups regarding the age

\begin{tabular}{|c|c|c|c|}
\hline & $\begin{array}{c}\text { Group A } \\
(\mathbf{n = 3 0})\end{array}$ & $\begin{array}{c}\text { Group B } \\
(\mathbf{n = 3 0})\end{array}$ & P-value \\
\hline $\begin{array}{c}\text { Age } \\
\text { (mean } \\
\pm \text { SD) }\end{array}$ & $\begin{array}{c}4.5 \pm 3.1 \\
(6 \text { months }-10 \\
\text { years })\end{array}$ & $\begin{array}{c}4.9 \pm 4.9 \\
(6 \text { months }-12 \\
\text { years })\end{array}$ & $>\mathbf{0 . 0 5}$ \\
\hline
\end{tabular}

Table (2): Examination of abnormal meatus

\begin{tabular}{|c|c|c|c|c|}
\hline & & $\begin{array}{c}\text { Group A } \\
(\mathbf{n}=\mathbf{3 0})\end{array}$ & $\begin{array}{c}\text { Group B } \\
(\mathbf{n}=30)\end{array}$ & p-value \\
\hline \multirow{3}{*}{$\begin{array}{l}\text { Site of abnormal } \\
\text { meatus No. }(\%)\end{array}$} & Glanular & $2(6.7 \%)$ & $6(20 \%)$ & \multirow[t]{3}{*}{$>0.05$} \\
\hline & coronal & $9(30 \%)$ & $8(26.7 \%)$ & \\
\hline & Distal penile & $19(63.3 \%)$ & $16(53.3 \%)$ & \\
\hline $\begin{array}{c}\text { Shape of abnormal } \\
\text { meatus No. }(\%)\end{array}$ & Stenotic & $6(20 \%)$ & $9(30 \%)$ & $>0.05$ \\
\hline
\end{tabular}

Table (3): local examination of the penis

\begin{tabular}{|c|c|c|c|}
\hline & $\begin{array}{c}\text { Group A } \\
(\mathbf{n}=30)\end{array}$ & $\begin{array}{c}\text { Group B } \\
(\mathbf{n}=30)\end{array}$ & p-value \\
\hline $\begin{array}{c}\text { Chordee of penis } \\
\text { No.(\%) }\end{array}$ & $\mathbf{5 ( 1 6 . 7 \% )}$ & $\mathbf{7 ( 2 3 . 3 \% )}$ & $>0.05$ \\
\hline $\begin{array}{c}\text { Skin of penis } \\
\text { No.(\%) }\end{array}$ & $\mathbf{2 5 ( 8 3 . 3 \% )}$ & $\mathbf{2 8}(\mathbf{9 3 . 3 \% )}$ & $>0.05$ \\
\hline $\begin{array}{c}\text { Circumcision } \\
\text { No.(\%) }\end{array}$ & $\mathbf{2 ( 6 . 7 \% )}$ & $\mathbf{4 ( 1 3 . 3 \% )}$ & $>0.05$ \\
\hline $\begin{array}{c}\text { Size of } \\
\text { penis(mean } \pm \text { SD) }\end{array}$ & $\mathbf{3 . 2 \pm 1 . 6}$ & $\mathbf{3 . 5} \pm 1.5$ & $>0.05$ \\
\hline
\end{tabular}

There was no statistically significant difference between both groups regarding time of the operation (table 4) or postoperative complications (Table 5). 
Table (4): Intraoperative time

\begin{tabular}{|c|c|c|c|}
\hline & Group A & Group B & p-value \\
\hline Operative time (mean \pm SD) & $2.1 \pm 0.3$ & $2 \pm 0$ & $>0.05$ \\
\hline
\end{tabular}

Table (5): Postoperative complications

\begin{tabular}{|c|c|c|c|c|}
\hline \multirow{2}{*}{ Haematoma } & \multicolumn{2}{|c|}{ Group A } & \multicolumn{2}{c|}{ Group B } \\
\cline { 2 - 5 } & No. & \% & No. & \% \\
\hline Meatal stenosis & 2 & $6.7 \%$ & 3 & $10.0 \%$ \\
\hline Glans dehisence & 4 & $13.3 \%$ & 3 & $10.0 \%$ \\
\hline Detrusor spasm & 1 & $3.3 \%$ & 0 & $0.0 \%$ \\
\hline Post operative retention & 6 & $20.0 \%$ & 0 & $0.0 \%$ \\
\hline infection & 0 & $0 \%$ & 7 & $23.3 \%$ \\
\hline Urethrocutaneous fistula & 7 & $23.3 \%$ & 4 & $13.3 \%$ \\
\hline
\end{tabular}

Regarding the factors affecting fistula formation postoperatively, transverse diameter of the glans, incision of the urethralplate (deep or shallow), Dartos flap (double), toilet without training can affect the fistula rate postoperatively (Table 6).

Table (6): Difference between both groups according to postoperative fistula

\begin{tabular}{|c|c|c|c|c|}
\hline \multicolumn{2}{|c|}{ Parameter } & $\begin{array}{c}\text { Stented group } \\
\text { complicated with } \\
\text { fistula }\end{array}$ & $\begin{array}{c}\text { Unstented group } \\
\text { complicated with } \\
\text { fistula }\end{array}$ & p-value \\
\hline \multirow{2}{*}{ Diameter of the urethral plate } & $\begin{array}{c}\text { Less than } \\
8 \mathrm{~mm}\end{array}$ & $6(33.3 \%)$ & $4(44.4 \%)$ & $>0.05$ \\
\cline { 2 - 5 } & $\begin{array}{c}8 \mathrm{~mm} \text { or } \\
\text { more }\end{array}$ & $1(8.3 \%)$ & $1(4.7 \%)$ & $>0.05$ \\
\hline \multirow{2}{*}{ Transverse diameter of the glans } & $\begin{array}{c}\text { Less than } \\
14 \mathrm{~mm}\end{array}$ & $3(21.4 \%)$ & $4(57.1 \%)$ & $<0.05$ \\
\cline { 2 - 5 } & $\begin{array}{c}14 \mathrm{~mm} \text { or } \\
\text { more }\end{array}$ & $4(25 \%)$ & $1(4.3 \%)$ & $<0.05$ \\
\hline \multirow{2}{*}{ Incision of the urethral plate } & deep & $3(13 \%)$ & $0(0 \%)$ & $<0.05$ \\
\cline { 2 - 5 } & shallow & $4(57.1 \%)$ & $5(100 \%)$ & $<0.05$ \\
\hline \multirow{2}{*}{ Dartos flap } & single & $2(16.6 \%)$ & $4(40 \%)$ & $>0.05$ \\
\cline { 2 - 5 } & double & $5(27.7 \%)$ & $1(5 \%)$ & $<0.05$ \\
\hline \multirow{2}{*}{ Toilet training } & trained & $3(20 \%)$ & $4(40 \%)$ & $>0.05$ \\
\cline { 2 - 5 } & Not trained & $4(30.7 \%)$ & $1(5 \%)$ & $<0.05$ \\
\hline \multirow{2}{*}{ Shape of the glans } & conical & $4(22.2 \%)$ & $3(21.4 \%)$ & $>0.05$ \\
\cline { 2 - 5 } & splayed & $3(25 \%)$ & $2(12.5 \%)$ & $>0.05$ \\
\hline \multirow{2}{*}{ Shape of the urethral plate } & shallow & $3(42.9 \%)$ & $3(60 \%)$ & $>0.05$ \\
\cline { 2 - 5 } & deep & $4(17.4 \%)$ & $2(8 \%)$ & $>0.05$ \\
\hline
\end{tabular}


There was statistically significant difference between both groups regarding mean hospital stay and mean dressing time (Table 7)

Table (7): postoperative data

\begin{tabular}{|c|c|l|c|}
\hline & Group A $(\mathrm{n}=30)$ & Group B(n=30) & p-value \\
\hline Hospital stay days & $1.9 \pm 0.8$ & $1.2 \pm 0.4$ & $<0.001$ \\
\hline Dressing (day) & $6.1 \pm 0.9$ & $1 \pm 0$ & $<0.001$ \\
\hline Catheterization period (day) & $4.6 \pm 1.4$ & --- & -- \\
\hline
\end{tabular}

\section{DISCUSSION}

This study was designed to compare incidence of common complications of Snodgrass repair with and without stenting the urethra using indwelling urethral catheter of distal penile hypospadias.

There was no significant difference between mean ages of the two groups. The age for majority of our patients presented to our hospitals is older as compared to other similar studies. As O'Sullivan et al. ${ }^{(7)}$ study in 2006 in which the median age of the patients was as low as 21 months and to another study by Aslan $\boldsymbol{e t}$ al. ${ }^{(4)}$ in 2007 in which the median age was 40.4 months and this is probably due to poor socioeconomic and low educational state of our patients, and mostly due to a delay in patient referral for intervention from primary outpatient's administrative assessment centers after diagnosis.

After preoperative evaluation urethroplasty was done in all 60 patients by TIP procedure. In Group-A patients, stent was removed at $5^{\text {th }}-7^{\text {th }}$ postoperative day as Snodgrass (8) recommended ending urinary diversion after a week.

In this study 7 patients (23.3\%) in group-A and 5 patients $(16.7 \%)$ in group-B developed urethrocutaneous fistula. In the stented group, the fistulas were evident on the day of stent removal in 2 cases and on the day after stent removal in 5 cases and in non-stented group one fistula was evident on $6^{\text {th }}$ postoperative day and the others on $7^{\text {th }}$ postoperative day. The fistula in the stented group was probably developed due to pressure ischemia or continuous irritation of suture line by stent. Fistula formation incidence here was much higher than that seen in other studies of hypospadias TIP repair which is from 7 to $16 \%$, it may be due to repair at elder age. It is widely reported in the literature that an older age at time of surgery increase complication rate. Perlmutter et al. ${ }^{(9)}$ in 2006 showed that the rate of complication in children younger than six months is less than older ones.

Shenoy et al. ${ }^{(3)}$ in 2016 documented that complications in the postoperative period post TIP included mainly postoperative fistula formation which occurred in 8 of the 30 cases of their study (26\%) irrespective of stent duration.

It is clear that our meatal stenosis rate in this study was different from Snodgrass documentation regarding meatal stenosis, and similar and equal to all other studies.

In the study by O'Sullivan et al. ${ }^{(7)}$ there was meatal stenosis in 3 of the 39 cases. In another study using Snodgrass repair done by Holland $\boldsymbol{e t}$ al. ${ }^{(10)}$ meatal stenosis was present in 3 of the 60 cases.

Regarding postoperative urine retention it happened in group (B) in 7 cases $(23.3 \%)$ of which one case $(3.3 \%)$ relieved with suprapubic aspiration once, and 6 cases $(20.1 \%)$ relieved with urethral catheterization once without fixation of the catheter, no cases needed suprapubic cystostomy.

Incidence of retention in this study are equal with the study of El-Sherbiny ${ }^{(11)}$. $\mathrm{He}$ concluded that placement of a stent reduces the rate of retention and urinary extravasation in toilet trained children post TIP urethroplasty, although other studies by Scarpa et al. ${ }^{(12)}$ concluded lower incidence $^{(3)}$.

Postoperative stay is an important consideration in elective procedure like hypospadias repair, The mean hospital stay was 1.9 days (1-3 days) in group (A) and 1.2 days (1-2 days) in group "B" with statistically significant difference between both groups.

In a study by O'Sullivan majority of the cases were treated as a day cases while most of the admitted cases were discharged on the next day of surgery ${ }^{(7)}$. However in study by Shenoy et al. ${ }^{(3)}$ due to various infrastructural and technical problems; it was not possible to operate hypospadias patients on a day care basis. Furthermore due to majority of study patients were hailing from the rural area and far distance it was not possible to cut short postoperative stay as follow up on a regular basis was not possible for most of such patients ${ }^{(3)}$.

In the study done by McCormack et al. ${ }^{(13)}$ in 1993 it was seen that urethral stents prolong 
hospital stay even by removal of the stent early or not placing a stent at all.

Moussavi et al. ${ }^{(14)}$ concluded that in 6 cases with distal hypospadias in which no stent was placed the postoperative period was less than 6 days. It was only increased to more than 6 days in 3 of the 6 patients in which stent were placed, but this difference was not statistically significant.

No uroflowmetry work was done for our cases as our study had included many children who were not toilet-trained and data analysis wouldn't achieve true result

Lorenzo et al. ${ }^{(15)}$ suggested performing uroflowmetry for all toilet-trained cases 6 months after surgery to treat asymptomatic stenosis.

Turial et al. ${ }^{(1)}$ reported good results with unstented repair, they used bladder silicon indwelling catheter in the stented group like our group (A) cases.

Pippi et al. ${ }^{\left({ }^{16)}\right.}$ analysed the complications rate in primary distal hypospadias repair defining a mean fistula rate of $5.9 \%$ (range $0-16 \%$ ). They suggested that surgeon experience and high volume of cases contribute to reduce the number of complications in any series, pointing out that small studies usually report a higher number of complications. Generally a urinary stent is maintained in situ for 2-7 days postoperatively ${ }^{(16)}$.

Steckler and Zaontz ${ }^{(17)}$ reported their excellent experience with stent-free repairs in 33 patients. On the other hand, in 2003 El-Sherbiny (11) obtained discouraging results in 64 toilettrained children with a median age of 6 years. In that prospective study an increase of urinary retention and reoperations was observed (even if not statistically significant), they used soft plastic urethral catheter in the stented group.

\section{CONCLUSION}

Considering the case series reported in the literature and data of this study, it could tell that removing the catheter can reduce bladder spasm and urinary tract infections, patient discomfort and improve the familiar compliance without increasing acute urinary retention episodes and fistula rate after TIP. so that, at least in some cases specially in distal types, leaving the stent can be avoided, although further studies should be conducted on this topic to clarify the role of postoperative stenting in distal hypospadias repair. Further case control studies with adequate sample size, will probably clear the possible doubts.

\section{REFERENCES}

1. Turial S, Enders J, Engel V et al. (2011): Stent-free tubularized incised plate (TIP) repair of distal and midshaft hypospadias irrespective of age. Eur J Pediatr Surg., 21(3):168-1 70.

2. Snodgrass W (2005): Procedure in distal and midpenile hypospadias. Pediatr Surg Int., 20: 197-199.

3. Shenoy NS, Kumbhar V, Shenoy Y et al. (2016): Outcome of hypospadias repair - stentless versus stented repair. Int Surg J., 3(4):2167-2172.

4. Aslan AR, Yücebaş E, Tekin A et al. (2007): Shortterm catheterization after TIP repair in distal hypospadias: who are the best candidates? Pediatr Surg Int., 23(3): 265-9.

5. Buson H, Smiley D, Reinberg Y et al. (1994): Distal hypospadias repair without stents: is it better? J Urol., 151(4): 1059-60.

6. Minevich E, Pecha BR, Wacksman J et al. (1999): Methieu Hypospadias repair: Experience in 202 patients. J Urol., 162: 2141.

7. O'Sullivan O, Bannon CA, Flood H et al. (2006): The Snodgrass repair: is stenting always necessary? LR Med J., 99(3):71-3.

8. Snodgrass W, Koyle M, Manzoni G et al. (1996): Tubularized incised plate hypospadias repair: Results of a multicenter experience. J Urol., 156 (2 Pt 2): 839841.

9. Perlmutter AE, Morabito R, Tarry WF et al. (2006): Impact of patient age on distal hypospadias repair: A surgical perspective. Urology, 68(3): 648-51.

10. Holland J, Keating MA, Snyder HM et al. (2000): Preservation of the urethral plate in hypospadias repair: extended applications and further experience with the onlay island flap urethroplasty. J Urol., 143: 98-100.

11.El-Sherbiny MT (2003): Tubularized incised plate repair of distal hypospadias in toilet-trained children: should a stent be left? BJU Int., 92(9): 1003-5.

12. Scarpa K, Lehner M, Schuster $T$ et al. (2005): Tubularized incised plate (TIP) urethroplasty (Snodgrass) in primary hypospadias repair. Eur $\mathbf{J}$ Pediatr Surg., 15: 420-424.

13. McCormack M, Homsy $Y$ and Laberge $Y$ (1993): No stent, no diversion Mathieu hypospadias repair. Can J Surg., 36(2):152-54.

14. Moussavi SA, Aarabi M (2014): Tubularized incised plate urethroplasty with or without stent in Hypospadias repair: a systematic review and metaanalysis Journalof Pediatric Rev., 2(2):2-11.

15.Lorenzo AJ, Snodgrass WT (2002): Regular dilatation is unnecessary after tabularized incised-plate hypospadias repair. BJU Int., 89(1): 94- 7 .

16.Pippi S, Arab S and Mitre AI (2008): Penoscrotal hypospadias. Braz J Urol., 26(3):304-314.

17.Steckler RE, Zaontz MA (1997): Stent-free Thiersch-Duplay hypospadias repair with the Snodgrass modification. J Urol., 158:1178-1180. 